\title{
Parametric variation and scrambling in English
}

\author{
Roland Hinterhölzl \\ Humboldt University
}

This is an offprint from:

C. Jan-Wouter Zwart and Werner Abraham (eds.) Studies in Comparative Germanic Syntax: Proceedings from the 15th Workshop on Comparative Germanic Syntax

(Groningen, May 26-27, 2000)

John Benjamins Publishing Company Amsterdam/Philadelphia

$$
2002
$$

Published as Vol. 53 of the series

LINGUISTIK AKTUELL / LINGUISTICS TODAY, Series editor: Werner Abraham, ISSN 0166-0829

\footnotetext{
ISBN 9027227748 (Eur) / 1588112683 (US) (C) 2002 - John Benjamins B.V.
}

No part of this book may be reproduced in any form, by print, photoprint, microfilm or any other means, without written permission from the publisher.

\section{Introduction and outline}

In the Principles and Parameters approach, word order differences between languages have been explained by assuming parametric variation in the headcomplement order. To explain the differences in word order between German and Dutch on the one hand and English on the other hand, it was assumed that in the Westgermanic SOV-languages the functional and lexical projections in the IP domain are head-final.

In a framework subscribing to the universal base hypothesis (Kayne 1994, Chomsky 1994), word order differences have to be related to other properties.

In the different installments of the Minimalist Program (Chomsky 1993, 1994), the desideratum is established that parametric differences between languages be reducible to morphological differences of the lexical items of these languages. Along these lines, Vikner (1997) tried to relate the extent of overt $\mathrm{V}$-movement in languages to the "strength" of the morphological paradigm of regular verbs in those languages.

Zwart (1993) proposed that OV-orders are the result of overt movement of the object into AgrOP, while VO-orders result from covert movement of the object to a licensing agreement position. In a similar vein, the difference in the position of the direct object vis-a-vis the verb between English and German can be related to the "strength" of the case morphology of the nouns in these languages. However, if one looks at the situation in Dutch - OV-order but no Case-morphology - one realizes that the strength of Case-features in Dutch comes out as a rather arbitrary property. 
Moreover, if we look at the different positions that verb-particles, small clause predicates and argument-PPs occupy in, say, English and German, then it becomes doubtful whether any morphological property of these elements can be found that could be held responsible for these differences.

A property that correlates with the position of the object with respect to the verb and that has received little attention in this connection so far, is the position of so-called event related adverbs, that is, Time, Place and Manner adverbs. These adverbs occur preverbally in the order $\mathrm{T}>\mathrm{P}>\mathrm{M}$ in OV-languages but postverbally in the exact mirror image in VO-languages, as is illustrated in (1).

(1) a. C TPM $-\mathrm{V}$ OV-languages

$$
\text { b. C V-MPT VO-languages }
$$

It is clear that this difference cannot be simply explained by differences in the scope of V-movement. Haider $(1993,2000)$, subscribing to the universal base hypothesis, proposed that SOV is the underlying base order from which SVO orders are derived by head movement of the verb, necessary to license its arguments in the canonical licensing direction of the language (left in German, but right in English).

The distribution of event related adverbs in these languages - if one order is to be derived from the other - must involve movement of more complex categories, since the unmarked order of these adverbs is TPM in German but MPT in English.

Given Cinque's seminal work on adverbs, these adverbials are peculiar in several respects (cf. Cinque 1997):

a. they appear to differ from adverbphrases (AdvPs) proper in not being rigidly ordered;

b. in contrast to AdvPs proper, they can be interchangeably in each other's scope, as is illustrated in (2);

(2) a. They met students everyday of the week in a different university b. They met students in each university on a different day

c. they differ from AdvPs proper in being typically realized in the form of PPs or bare NPs. I assume that this property explains the former two properties: being PPs or NPs, they have the potential for scrambling which may move them out of their base position to other positions according to their quantificational or referential properties. And d. scope may go from right to left (cf. (3a)), but binding only from left to right, as is illustrated by the contrast in $(3 b, c)$.

(3) a. John met Mary in a (different) park every Sunday

b. *Sue met Mary in his house on everybody's birthday

c. Sue met Mary on everybody's birthday in his house

The standard account of postverbal adverbs in VO-languages was given in terms of layered adjunction to the VP on the right. This account not only violates the Linear Correspondence Axiom (LCA) of Kayne (1994), but also fails to account for binding relations as illustrated in (4).

(4) She met every student on his $_{\mathrm{i}}$ birthday

Pesetsky (1995) proposed to resolve this paradoxical situation by assigning a dual structure to each clause: a layered one and a cascading one. The layered structure accounts for the basic constituent structure pertaining to postverbal complements and adjuncts. The cascading structure provides the relevant c-command relations for binding.

In this article, I argue that there is a better solution to Pesetsky's paradox that does not involve a dual structure and that this solution implies that English has scrambling. Furthermore, I argue that scrambling of DPs in English is 'silent', that is to say, that it involves Spell-out of the lower copy. The article is organized in the following way.

In Section 2, I discuss Pesetsky's paradox in more detail. I present two arguments that the cascading structure is untenable and that the layered structure in English is to be derived (via successive cyclic intrapositon of verbal projections) from the German order (cf. (1)) obeying the LCA. Finally, I propose that the binding facts should be accounted for in terms of scrambling of the arguments of the verb. In Section 3, I outline a minimalist theory of parametric variation that accounts for the differences in verb movement and scrambling between English and Continental West Germanic. In Section 4, I give an overview of scrambling operations that occur in Dutch and German and discuss their properties and restrictions. From this discussion, it will follow that there is no reason to assume that English could not have the types of scrambling operations observed in Dutch. Finally, in Section 5, I provide some more arguments for silent scrambling in English. First, I discuss certain scope facts and argue that - in the absence of covert movement - they can be given the simplest explanation if it is assumed that scrambling is silent in English. Then, I discuss the phenomenon of antecedent-contained deletion (ACD) and show 
that scrambling, contrary to approaches based on Quantifier Raising (QR) and Case movement, can resolve all cases of $\mathrm{ACD}$.

\section{Pesetsky's paradox or What is the correct analysis of event related adverbs?}

The standard approach to the syntax of adverbs in English assumes that adverbs are right-adjoined to VP or I, as indicated in (5).

(5) [IP $_{\mathrm{SU}}$ [VP [VP V DO] Adjunct]]

Right-adjunction structures, either base generated or derived by movement, are incompatible with the universal base hypothesis. Independently of the universal base hypothesis, Larson (1988), Stroik (1990) and Pesetsky (1995) have argued that the standard approach to the syntax of adverbs is mistaken, since it fails to account for basic c-command relations between them and the complements of the verb. Typical c-command diagnostics, such as negative polarity item (NPI) licensing (6a) and quantifier-bound pronouns (6b), indicate that postverbal adjuncts are in the c-command domain of postverbal complements.

(6) a. John saw no student in any classroom

b. John visited everyone on his birthday

Since in the representation in (5) the direct object fails to c-command the postverbal adjunct, Larson (1988) proposed that event related adverb(ial)s are part of a (multi-) layered VP-shell in which these elements are deeper embedded than the complements of the verb as is indicated in (7).

(7) [ [vp SU V [ [vp DO t tv Adjunct]]]

\subsection{Against a Larsonian approach}

In the Larsonian approach, event related adverbs are analyzed as a sort of (optional) complements in the VP. While the Larsonian approach neatly accounts for the c-command effects illustrated in (6), it fails to account for standard constituency tests such as VP-fronting. The latter process indicates, contrary to the state of affairs in (7), that the verb and the direct object form a constituent which excludes adjuncts (8c). On the other hand, constituents of Larsonian shells motivated by binding do not permit fronting (8d). These observations led Pesetsky into proposing an additional - layered — structure.
(8) John promised that he would visit them in Vienna on Friday, and...

a. visit them in Vienna on Friday, he did

b. visit them in Vienna, he did on Friday

c. visit them, he did in Vienna on Friday

d. *them in Vienna on Friday, he visited

To explain (8c) without an additional structure, it has to be assumed that the adjuncts are moved out of the VP, that is, are evacuated, before VP-fronting. This account raises several questions. First, it is not clear what the motivation for this evacuating movement should be. Secondly, it is not clear why this movement is restricted to the right-most constituent in each case. (9) shows that evacuating an intermediary adjunct leads to reduced acceptability.

(9) ?? visit them on Friday, he did in Vienna

In (9), the adjunct in Vienna has been extracted from a specifier position before VP-fronting takes place. To explain the contrast between (8b) and (9), one may propose that only complements may be evacuated. However, this account cannot be generalized, since the subject and the object, in the presence of an adjunct, occupy a specifier position in the Larsonian shell, but can be freely extracted from the VP.

Another problem with the Larsonian approach concerns the anti-c-command requirement in the licensing of parasitic gaps: the trace of the licensing operator may not c-command the parasitic gap. This derives the descriptive generalization that objects can license parasitic gaps in adjunct clauses, while subjects fail to do so (cf. (10a) versus (10b)). Since in the Larsonian approach, both subjects and objects c-command adjuncts, it is unclear how to account for this generalisation.

(10) a. Which article did you criticize before reading? b. ${ }^{*}$ Who saw you before you recognized?

The above noted problems with the Larsonian approach I consider minor or technical problems that may be overcome in a relatively simple fashion. In the following I present two arguments which I consider more detrimental to the Larsonian approach. The first argument involves the semantic interpretation of event related adverbs and the second argument pertains to the comparative dimension of accounting for the different distribution of these adverbs in OVand VO-languages.

First, the Larsonian approach to the syntax of event related adjuncts raises questions about the proper interpretation of these elements. In a Larsonian 
shell structure, temporal adverbs are deeper embedded than manner adverbs, as is shown in (11).

(11) a. John wrote the letter carefully today

b. [VP John wrote [ ${ }_{\mathrm{VP}}$ the letter $\mathrm{t}_{\mathrm{V}}$ [vP carefully $\mathrm{t}_{\mathrm{V}}$ today]]]

Following Ernst (1998), Haider (2000) and others, I assume that the attachment of adverbs is determined by their scopal properties. The scopal requirements of an adverb include selection for a clausal argument of a particular type. Ernst (1998) specifies a schema of abstract clausal entities relevant for the interpretation of adverb(ial)s.

\section{(12) Speech Act $>$ Fact $>$ Proposition $>$ Event $>$ Specified Event}

From (12) it follows, for instance, that evaluative adverbs like unfortunately selecting for a fact cannot attach lower to the clausal skeleton than modal adverbs like probably selecting for a proposition, though they can otherwise occupy various positions in the clause, as is illustrated in (13).

(13) a. (Unfortunately) Eddie (unfortunately) has ('unfortunately) left b. *Probably Eddie unfortunately has left

From a semantic point of view, manner adverbs specify an aspect of only part of the event, namely the process component of the event, while temporal adverbs situate the entire event with respect to the utterance time. Thus, standard assumptions about the interaction of syntactic structure and semantic interpretation predict that temporal adverbs should attach to the clause higher than manner adverbs, not lower, as in the Larsonian approach.

Secondly, here is what I call the comparative argument. If the English order is basic, then it is not clear how the German order is to be derived. A roll-up structure that moves a constituent containing the temporal adverb in front of the manner adverb and subsequently moves that larger constituent in front of the final position of the verb fails to account for the scopal properties of these adverbs in the middle field. In the German middle field an adverb always has scope over the adverb to its right. A derivation in terms of movement of the adverbs by themselves raises several questions. The straightforward derivation violates cyclicity as illustrated in (14).

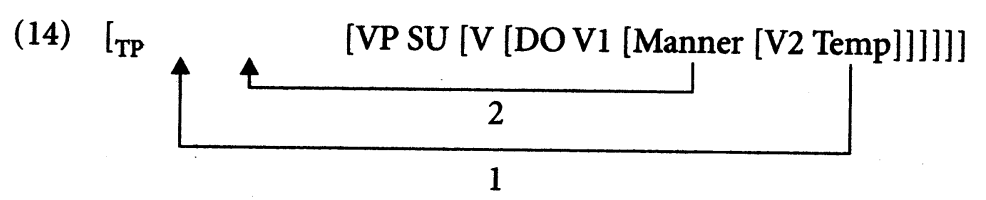

Though there is a derivation that obeys cyclicity - the one that moves the manner adverb and the direct object into the middle field before the temporal adverb is moved - , both derivations suffer from the circumstance that it is not clear what the motivation behind these obligatory movements should be. In other words, why is it that event related adverbs are apparently licensed in situ in English but have to undergo licensing movement in German? To the extent that we cannot find a satisfactory answer to this question, the Larsonian approach is rendered unattractive.

\subsection{For a comparative approach}

Given the above considerations, in particular, taking serious the semantic argument, it seems that the order of event related adverbs observed in German, namely $\mathrm{T}>\mathrm{P}>\mathrm{M}$, is closer to the base than the English order. Thus, I propose that the English order is derived from the German order via successive cyclic intraposition of verbal projections. ${ }^{1}$

In the following, I assume that manner adverbs are base generated in the VP while Time and Place adverbs are base generated above VP as is indicated in (15).

(15) [Temp ... [Loc ... [v [Manner [V DO]

Under these assumptions, the English sentence in (16a) is derived from the base structure in (16b) via successive intraposition as indicated in (16c).

(16) a. John visited them in Vienna on Friday

b. [IP $_{\mathrm{J}} \mathrm{John}_{\mathrm{i}}$ [on Friday [in Vienna [VP $_{\mathrm{i}}$ visited them]]]]

c. [IP John [[[visited them] in Vienna] on Friday]]

The representation in (16c) accounts for the VP-fronting facts illustrated in (8) and (9), but fails to account for the binding facts. To explain the data in (6), I assume that English has "silent" scrambling.

Silent scrambling means that there is an overt operation that moves the direct object of the verb into middle field, just like German scrambling moves the direct object out of the VP to a position preceeding adverbs in the middle field, but, unlike German, spells out the lower copy, as indicated by the underlining in (17). 
(17) a. [IP $\left.\mathrm{O}_{i}(\mathrm{Adv})\left[\mathrm{VP}_{\mathrm{V}} \mathrm{O}_{\mathrm{i}}\right]\right]$ scrambling in German

$$
\text { b. }{ }_{I P} \mathrm{O}_{\mathrm{i}}\left[\mathrm{VP}_{\mathrm{V}} \mathrm{V} \underline{\mathrm{O}}_{\mathrm{i}}\right] \text { 'silent'... the lower copy is spelled out }
$$

First note that scrambling, being an operation of A-movement, creates a new binding position to license bound pronouns and NPIs. As is shown in (18a,b), scrambling of the direct object across the temporal adverb can license the bound pronoun contained in the adverb. (19) shows that scrambling can license an NPI.

(18) a. *weil die Maria an seinem Geburtstag jeden $_{i}$ Freund besuchte since the Maria on his birthday every friend visited

b. weil die Maria jeden Freund an seinem $_{i}$ Geburtstag besuchte since the Maria every friend on his birthday visited

(19) a. *weil Hans jemals keinen Studenten traf since Hans ever no student met

b. weil Hans keinen Studenten jemals traf since Hans no student ever met

Also note that if we accept the semantic argument sketched above and assume that the English order is to be derived from the German order, in other words, if we dispense with the Larsonian approach to the syntax of event related adverbs, then scrambling is the only option to derive the binding facts in (6): the scrambling analysis is superior to an analysis in terms of a covert operation at LF, since quantifier raising would lead to a Weak Crossover (WCO) effect in the case of (6b).

To account for the contrast in (3bc), I assume that the restriction on pronoun binding displayed in these examples can be subsumed under a leftness condition on variable binding (cf. Hornstein 1994). But this restriction is independent of the scrambling approach and a problem for any analysis of the binding facts that obtain between postverbal adjuncts and arguments in English.

\subsection{Against the (revised) standard approach}

Given the option of silent scrambling, the question arises whether the standard approach to the syntax of adverbs in English in terms of right-adjunction would be simpler. In this account manner adverbs would indeed be attached lower than temporal adverbs. This alternative is viable but it raises a couple of nontrivial questions.

One has to assume not only that there is a parameter that specifies the attachment site of event related adverbs but also that this parameter is linked to the head-complement parameter. It is not at all clear why exactly event related adverbs but not the other adverbs of the clause (quantificational, aspectual, discourse related or focusing adverbs as well as predicational adverbs that take propositions and facts as arguments) are parametrized this way.

Secondly, there is the typological fact that scrambling, viewed as movement out of the VP into different positions - interspersed with adjuncts - in the middlefield, is found in OV-languages but absent in VO-languages. In the comparative approach in which it is assumed that adverbs are left-attached to the clause, the absence of audible scrambling in VO-languages can be explained in the following way. Right-peripheral adverbs require the assumption of VP-intraposition which process would "mask" prior scrambling of an argument across these adverbs for the language learner. In the standard approach, in which it is assumed that adverbs can be either left- or right-adjoined to the clause there is no connection between scrambling and the licensing of adverbs. In this approach, it is not clear why arguments cannot move into the middle field in VO-languages.

Another property of adverbs in VO languages that is in need of an explanation is the fact that adjuncts that can occur between the subject and the VP in VO-languages are subject to restrictions absent in OV-languages:

(20) a. John (more) often ( ${ }^{*}$ than Peter) read the book b. Hans hat öfter (als der Peter) das Buch gelesen Hans has more-often (than the Peter) the book read

Descriptively speaking, the head of the adjunct must not have material to its right. This is only possible if the adjunct appears in sentence final position, that is to say, if the adjunct is right-adjoined. An option, on the other hand, that is not available in OV-languages as the contrast illustrated in (21) shows.

(21) a. John read the book more often than Peter
b. ${ }^{\star}$ Hans hat das Buch gelesen öfter (als Peter)

Hans has the book read more-often (than Peter)

The above facts can be captured by the stipulation in (22) if we assume that the canonical position for adjunction is to the right in VO-languages and to the left in OV-languages.

(22) Only in the canonical adjunct position may the head of the adjunct take a complement 
(22) is problematic in at least two respects. First of all, it is not clear why there should be such a particular restriction like (22) in languages. Secondly, there are numerous counterexamples to this generalization in both English and German. In German, PPs and clauses, when extraposed, can freely occur in rightadjoined position though their respective heads $\mathrm{P}$ and $\mathrm{C}$ take a complement in these cases. In English, topicalized constituents which are analyzed as being leftadjoined to IP, that is, which are in a non-canonical adjunction position, can, of course, contain complements, as is illustrated in (23).

(23) a. When Mary came in, Peter went out

b. In the morning, Peter went out

c. More often than necessary, Peter went out

Thus the stipulation in (22) is far too general and it is not clear at all how to restrict it in the appropriate fashion.

In the comparative approach adverbs can only be left-attached. There is intraposition of verbal projections to license the verb in VO-languages as we will argue in Section 3. Assuming that the restriction exemplified in (20) has something to do with heavy material occuring in sentence-medial position, I propose that - since intraposition of verbal projections is available in VO-languages in general - it can be used for an operation that possibly applies at PF and moves light predicates across heavy adverbs such that the latter end up at the right periphery. Since the grammar of German does not have at its disposal an operation of intraposition of verbal projections, (21b) is ungrammatical.

In the following section, I will outline a theory of parametrization within which the differences between German and English can be explained without recourse to the head complement parameter or the notion of feature strength.

\section{Parametric variation and Which factors determine the Spell-out} of copies?

I assume that languages are essentially alike differing only in how they satisfy universal constraints. That is to say that I assume that all movement operations are overt. In particular, I assume that languages may differ in only two macroparameters:

A. Each feature may be checked via XP- or $\mathrm{X}^{0}$-movement

B. In checking a feature either the higher or the lower copy may be spelled out
With respect to Parameter A, I assume that there is a constraint 'Attract Closest' which implies that XP-movement is the unmarked option in feature checking. $\mathrm{X}^{0}$-movement is dependent on special requirements of the attracting head, for instance, on the attracting head being an affix.

Parameter A is relevant for the positioning of adverbs. When the English verb undergoes licensing movement, it does so by XP-movement (the unmarked option) which will result in inverted orders. When the German verb undergoes licensing movement, it does so by $\mathrm{X}^{0}$-movement, followed by remnant XP-preposing (cf. Hinterhölzl 2000, Haegeman 1999), which leaves preexisting orders unchanged.

With respect to Parameter B, I assume that in checking an uninterpretable feature, the higher copy must be spelled out. ${ }^{2}$

In checking an interpretable feature either copy may be spelled out unless the attracting head has a positional feature. A positional feature requires that the attractee is spelled out in the checking domain of the attractor (this is different from the notion of strong features). Typical examples of positional features are [wh], [neg] and [focus].

To illustrate the notion of a positional feature, let us look at the distribution of definite DPs in German. Definite DPs always have to move across negation, as is shown in (24ab). We may assume that this movement occurs to check a specificity feature of the NP. However, if the definite DP is focused, checking of the specificity feature may seemingly be dispensed with (24c).

(24) a. weil der Hans das Buch nicht gelesen hat since the Hans the book not read-PART has

b. * weil der Hans nicht das Buch gelesen hat since the Hans not the book read-PART has

c. weil der Hans nicht das BUCH gelesen hat since the Hans not the book-Focus read-PART has

This is a problem, since a feature that needs to be checked, should be checked alike in all contexts. A neat analysis of the facts in (24) is obtained, if we assume that the DP has in fact moved into the domain where specifics are licensed (that is above sentence adverbs including negation) but due to the positional feature of focus, is spelled out in the specifier position of a functional head which occurs below negation. Which head in a given language has a positional feature is subject to crosslinguistic variation.

I assume that Parameter B is relevant for the instantiation of scrambling. In particular, I assume that Spell Out is guided by economy considerations in the 
following manner. If a language has the basic word order $\mathrm{XY}$ and there is interpretative evidence for movement of $Y$, but no evidence for movement of $X$ then the simplest analysis is that $Y$ is spelled out in the lower copy. These Spell Out choices are fixed by an optimizing learning algorithm in the process of language acquisition. A child acquiring English will, on encountering interpretive evidence for scrambling but no evidence from the PF-side, assume that scrambling spells out the lower copy.

In the next section, I will provide a typology of scrambling operations in West-Germanic and show how scrambling in English fits into the picture.

\section{Silent scrambling: A typology of scrambling operations}

A careful investigation of scrambling operations in German and Dutch reveals that there are (at least) three types of scrambling operations whose properties are summarized in the table given below.

\begin{tabular}{|c|c|c|c|c|c|c|}
\hline Name & Motivation & $\begin{array}{l}\text { Permutation } \\
\text { of } \\
\text { arguments. }\end{array}$ & $\begin{array}{l}\text { Reconstruc- } \\
\text { tion }\end{array}$ & $\begin{array}{l}\text { moved item } \\
\text { bears stress }\end{array}$ & $\begin{array}{l}\text { creates new } \\
\text { binding } \\
\text { poutition }\end{array}$ & $\begin{array}{l}\text { Depends on } \\
\text { Case }\end{array}$ \\
\hline Permutation & Familiarity/Scope & yes & no & no & yes & yes \\
\hline Extension & Familiarity/Scope & no & no & no & yes: & no \\
\hline F-scrambling & Contrast & yes & yes & yes & $?$ & no \\
\hline
\end{tabular}

First, there is the type of scrambling known from German which allows movement of the object across the subject, as is illustrated in $(25 \mathrm{a}, \mathrm{b})$. It is this operation that can be held responsible for voiding WCO-effects $(25 b, c)$ and Superiority effects (25d) between subjects and objects in German.

(25) a. weil den Hans die Maria liebt since the-Acc Hans the-Nom Maria loves [since Mary loves John]

b. weil jeden $_{i}$ seine $_{i}$ Mutter liebt since everyone-ACc his-NOM mother loves [since his mother loves everyone]

c. Wen ${ }_{i}$ liebt seine ${ }_{i}$ Mutter nicht? whom loves his mother not [who does his mother not love] d. Wen hat wer geliebt? whom has who loved [who does who love]

e. weil jeden eine Frau liebt since everyone-ACC a-NOM woman loves [since some woman loves everyone]

I call this operation permutation since it allows for the arguments of the verb to be generated in any order. It is an operation of A-movement since it creates a new binding position (cf. (25b)) that cannot be reconstructed, as can be seen from the fact that sentences like (25e) are unambiguous.

Permutation is unavailable in Dutch, as is illustrated in $(26 \mathrm{a}, \mathrm{b})$.

(26) a. dat Jan de boeken niet koopt that Jan the books not buys

b. *dat de boeken Jan niet koopt that the books Jan not buys

But Dutch allows for scrambling of the arguments of the verb across adverbs that occur in the middle field as long as scrambling preserves the order of the arguments. I call this operation extension. Extension is a type of A-movement, as we have seen in (18) above, that like permution does not allow for reconstruction, since the resultant structures are unambiguous.

With permutation and extension, the moved item is unstressed. That there is a third type of scrambling is most clearly shown by Dutch. As was shown in (26), the direct object can generally not move across the subject. However, there is a type of scrambling which Neeleman (1994) called focus-scrambling, but really involves movement of a contrastive topic, which exactly does that, as is shown in (27a). This operation comes with a special intonational contour (the so-called hat contour, with a rise on the moved item and a fall on the focused element), obligatorily requires a (contrastively) focused element in the remainder of the clause and is to be conceived as an A-bar movement operation, since it may not only affect arguments, as permutation and extension exclusively do, but also predicates, as is illustrated in (27b).

(27) a. dat zulke boeken zelfs JAN niet koopt that such books even Jan-rocus not buys

b. dat rood zelfs JAN het hekje niet verft that red even Jan-rocus the fence not paints 
One may wonder why two types of A-scrambling have to be distinguished and what their respective motivations are. As has been noted before (cf. Diesing 1992), scrambling often comes with a specificity effect. (I use the term familiarity to encompass DPs that are familiar from the linguistic as well as the nonlinguistic context).

That A-scrambling cannot be reduced to the sole trigger of specificity/ familiarity is shown in (28).
(28) weil jeder
zwei Bücher einer Frau schenkte since everyone-NOM two books-ACC A-DAT woman gave

(intermediate scope possible)

In (28), the direct object has scrambled across the indirect object but remains in the scope of the subject. If A-scrambling necessarily came with a specificity effect, then the direct object should have only widest scope in (28). Since an intermediate scope-reading is possible A-scrambling must be able to have an additional trigger which I identify with scope-taking.

I assume that permutation and extension can target the same positions. In German, additional positions are available which allow for the permutation of arguments. I identify these positions as the specifiers of functional heads hosting clitics and assume that these positions are accessible for DPs in a language, if Case in that language distinctively marks grammatical functions. This is the case in German but not in Dutch or Icelandic.

Older stages of Dutch and English had scrambling of the German type. Dutch probably lost permutation when it lost its Case distinctions in the nominal system (which are partially preserved in the pronominal system). Given these observations, it seems reasonable to assume that English preserved scrambling of the Dutch type, that is, extension and F-scrambling.

In the final section, I present an additional argument for the conjecture that English has scrambling, as well as some observations that speak for the silent character of scrambling in English.

\section{Evidence for silent scrambling}

Let me first expand on why I think scrambling is silent in English. If English has scrambling of the Dutch type, then we expect that the direct object can be separated from the verb by adverbs in the middle field. This is generally not the case. In particular, the direct object cannot be separated from the verb by a postverbal manner adverb. Note that due to VP-intraposition this state of affairs is actually expected, as is illustrated in (29). In (29c), the VP has to move higher than the scrambled direct object (DO) in accordance with the extension condition on derivations.

$\begin{array}{llll}\text { (29) } & \text { a. } & [\mathrm{C} \ldots[\text { Manner }[\mathrm{VP} V \mathrm{DO}]]]] & \text { base structure } \\ \text { b. } & \left.\left[\mathrm{C} \ldots \mathrm{DO}_{\mathrm{i}}\left[\mathrm{Manner}_{\mathrm{VP}} \mathrm{V} \mathrm{DO}_{\mathrm{i}}\right]\right]\right] & \text { scrambling } \\ \text { c. } & \left.\left[\mathrm{C} \ldots\left[\mathrm{VP}_{\mathrm{VP}} \mathrm{VDO}_{\mathrm{i}}\right] \mathrm{DO}_{\mathrm{i}}\left[\mathrm{Manner}_{\mathrm{VP}}\right]\right]\right] & \text { VP-intraposition }\end{array}$

(29c) does not tell us anything about whether scrambling is silent or 'audible' in English: Spell Out of either copy of the direct object derives the correct word onder. However, if we look at more complex structures, then we realize that scrambling in English must be silent. (30) shows that the direct object may have scope with respect to two adverbs, while the expected word order that the scope taking scrambling operation (across both adverbs) yields, is impossible.

(30) a. John met every woman twice on a Sunday b. *John met twice every woman on a Sunday

In (30), the direct object may have scope over Sunday and twice, which is actually the prevalent reading $(W>S>t)$. If scrambling in English were audible then the wide scope reading in (30) would require additional movement of the verb and the direct object to derive the correct word order. The simplest option of deriving this reading with the word order given in (30a) is to assume that scrambling is silent in English.

Note, by the way, that the impossible English order in (30b) is licit in another VO-language, Italian. Diana Pili (2000) reports that the order $V$ Manner - DO- higher $A d v$ is possible in Italian.

Finally, I would like to discuss a phenomenon that supports my conjecture that English has scrambling. The assumption of (silent) scrambling has the advantage that it can account for all cases of antecedent-contained deletion (ACD). There are two types of explanations that posit covert movement for ACD-resolution: $\mathrm{QR}$ and covert Case driven movement to AgrOP. Within these approaches it is agreed that movement of the direct object out of the VP is necessary to create the proper antecedent, the V-trace-configuration, that can be copied into the ellipsis site, as is illustrated in (31).

(31) a. Mary invited everyone that I did

b. Mary [everyone that I [e]] invited $t \quad[\mathrm{e}]=[$ invited $t]$

May (1985) has argued that the phenomenon of ACD provides good evidence for the existence of $\mathrm{QR}$, since only quantified expressions but not referential 
expressions can resolve cases of $A C D$, as the contrast between (31a) and (32a) shows.

(32) a. *Mary invited Peter who I did

b. Mary invited Peter, who Susan also did

However, Cases of ACD involving names are not impossible in general. (32a) improves considerably if the relative clause expressed some contrast to the previous clause, that is, if it contains some focused element, as is illustrated in (32b). Since names are not the type of elements that can reasonably be assumed to be in need of QR for the sake of their interpretation, QR-based approaches have problems with ACD involving referential expressions like names (Vanden Wyngaerd and Zwart 1991). This observation led Hornstein (1994) into proposing that cases of ACD are resolved by Case-driven movement into AgrOP in English, the argument being that both referential and quantificational DPs are in need of Case. Note, however, that Case-movement-based explanations have problems with NP-contained ACD, as has been pointed out by Kennedy (1997) and Pesetsky (2000). The interpretation of (33a), given in (33b), involves movement of the PP out of the containing NP a report, which cannot possibly be motivated with the need for checking Case.

(33) a. Mary read a report on every murder the police did

b. every murder Mary read a report on, the police read a report on

c. weil Maria über jeden Mordfall einen Bericht las since Maria about each murder a report read

Note, however, that scrambling can be argued to be able to resolve all the cases of ACD illustrated in (31)-(33). Names and QPs scramble alike in German, though due to different motivations as we have seen in the previous section. And scrambling may also move a PP out of an NP, as is illustrated in (33c), as long as the NP is indefinite, which is exactly the restriction that applies to cases of NP-contained ACD.

The assumption of silent scrambling may even provide us with an explanation for the restriction on ACD involving names that is illustrated in (32ab). Let us make the reasonable assumption that each movement operation must be either PF- or LF-interpretable. Silent scrambling never has a PF-effect and will thus be only licit if it has an LF-effect. However, scrambling of names is not interpretable in terms of scope, since a name, independently of its position, is always interpreted in the same way, namely, with widest scope. It thus follows that silent scrambling of names cannot be extension-scrambling but must be
F-scrambling which, as we showed in the previous section, necessarily involves a focused constituent which sets up the required contrast.

Since I propose that cases of ACD are better not treated as being resolved by the operation of $Q R$, the question arises whether $Q R$ plays any role in English and in language in general. In the spirit of Kayne (1998), it would be advantageous to have a grammar without postcyclic rules, that is to say, a grammar in which all operations occur overtly in a cyclic fashion. Two phenomena immediately come to one's mind which were traditionally taken as evidence for the existence of QR: cases of inverse scope and cases of inverse linking, illustrated in $(34 \mathrm{a}, \mathrm{b})$, respectively.

\section{(34) a. Someone loves everyone}

b. Some inhabitant of every city hates its traffic

Let us talk about cases of inverse scope (34a) first. The ambiguity of (34a) should not be explained in terms of reconstruction of the subject to its base position below the object in SpecAgrOP, since then we would not expect a Weak Crossover effect in cases like (35a) below. Thus the ambiguity should be explained in terms of movement of the object across the subject. Such an operation is QR or scrambling as is shown in the German example (35b).

(35) a. ${ }^{*}$ His $_{\mathrm{i}}$ mother loves everyone $\mathrm{i}_{\mathrm{i}}$

b. weil jeden $n_{i}$ jemand $t_{i}$ liebt

since everyone someone loves

'for everyone there is someone that loves him'

Let us assume that $\mathrm{QR}$ does not exist. If scrambling is to do the job (involving a Spell-out of the lower copy marked by the trace in (35b)), then the inverse scope in (34a) can only be achieved by applying f-scrambling, since extension, as we have seen in (26) for Dutch, cannot move objects across subjects. F-scrambling being an operation of A-bar movement will induce a WCO-effect in (35a). Thus we derive the desired effect, that no WCO-effect is induced with respect to binding of pronouns contained in event related adjuncts (since the A-movement operation of extension is available there), while a WCO-effect obtains when a bound pronoun is contained within the subject. Furthermore, we predict that the inverse scope reading in (34a) is not freely available but comes with a special intonation. Most native speakers I have asked agree with this judgment but I have not been able to find out whether the special intonation is the same intonational contour that is typically related with f-scrambling in Dutch and German. 
The standard account of the case of inverse linking in (34b) involves $Q R$ of the universal quantifier that adjoins it to IP, from which position it can bind the pronoun in the object. Note that this case is more recalcitrant, since the parallel operation of overt scrambling of the possessive DP out of the containing DP is not available in all cases in German. Extraction of a PP out of a transitive subject is generally ungrammatical, as is shown for the parallel case to (34b) in (36a). In addition, binding of a pronoun outside of the containing DP is impossible in this case in German, as is shown in (36b).

(36) a. *weil von jeder Stadt [ein Einwohner $t$ ] den Verkehr haßt since of each city an inhabitant it hates

b. * weil ein Einwohner von [jeder Stadt $]_{i}$ ihren $_{i}$ Verkehr haßt since an inhabitant of every city its traffic hates

Furthermore, note that, abstracting away from binding the pronoun, (36b) is not ambiguous in German. It can only have the absurd reading that someone who lives in every city hates (some) traffic. ${ }^{3}$ If $\mathrm{QR}$ is the solution to cases like (34b), then the question arises why $\mathrm{QR}$ is available in English, but not in parallel cases in German. Instead, I would like to argue that the difference between (34b) and (36b) be related to another difference between German and English, which points to a difference in the structure of DP between the two languages.

In German, a prenominal possessor, contrary to the state of affairs in English, cannot bind a pronoun outside of the containing DP, as is shown in (37b). Again, if (37a) is to be explained in terms of $Q R$, then the question arises, why $Q R$ is possible in English but not in the parallel German case.

(37) a. Every man's 's mother loves him

b. ${ }^{*}$ Jedermanns $s_{\mathrm{i}}$ Mutter liebt ihn $\mathrm{i}_{\mathrm{i}}$

Kayne (1994:26) proposes that the English DP contains two specifier positions, a lower one hosting genitive subjects and a higher one which he identifies as an operator position and which in his system allows for c-command out of the DP. We may assume that it is movement to this position which is responsible for the inverse reading in (34b) and that this position, for some reason, is unavailable in German. If this is correct, then QR is not needed to explain cases of inverse linking in English: movement of the relevant DP to the high operator position is sufficient to license inverse scope as well as the bound pronoun and makes extraction out of DP superfluous. In German, inverse linking and a DP external bound pronoun are only possible if extraction is possible. This is illustrated in (38) where the PP is extracted from a direct object DP.
(38) weil Maria über jeden Schauspieler [eine Broschüre t] an seinen since Maria about each actor a brochure to his Agenten schickte

agent sent

\section{Conclusion}

To summarize, I have outlined Pesetsky's paradox which involves the assignment of a dual structure to sentences containing event related adjuncts. I presented two arguments showing that the Larsonian approach to event related adverbs, which derives Pesetsky's cascading structure to account for the c-command properties between postverbal complements and postverbal adjuncts is mistaken. Then, I argued that Pesetsky's layered structure is to be derived from a corresponding right-branching structure, directly observable in German and Dutch, via successive cyclic VP-intraposition. I proposed that the interpretational effects yielded by Pesetsky's cascading structure are derived by the operation of scrambling in English. I argued that scrambling in English is silent, that is to say, must involve Spell-out of the lower copy, and provided further evidence for silent scrambling by showing that silent scrambling, in distinction to QR or Case-based movement can account for all cases of ACD in English.

Furthermore, I outlined a minimalist theory of parametric variation within which the differences in object and adverb placement in English on the one hand, and Dutch and German on the other hand, can be accounted for without recourse to an underlying head-complement parameter or the notion of feature strength.

Finally, I addressed the question of the (residual) role of $\mathrm{QR}$ in the syntax of English. I discussed cases of inverse scope and inverse linking and argued that they are better accounted for without making use of the operation of $Q R$.

Notes

1. There is another base structure given in (i) that respects the semantic condition outlined in the text:

(i) [[[VP [e Manner]] e Loc] e Temp]

The structure in (i), however, raises several questions. First, it is not clear how the empty heads of verbal type which introduce event related adverbs as their complement and take the VP hosting the arguments of the lexical verb as their specifier, are identified. Secondly, we need to allow for projection to proceed via the specifier, since we want that functional heads 
above VP belong to the extended projection of the lexical verb. Thirdly, it suffers from the same defect as the Larsonian structure: to derive the German (Dutch) order, individual obligatory movement of the adverbs into the middle field has to be assumed, the motivation of which remains obscure.

2. Following Nuñez (1995), I propose that in a checking operation only the pertinent features of the merged copy are checked. The uninterpretable features of the lower copy can then only be gotten rid of by phonological deletion, which encompasses formal features in Nuñez' system.

3. The inverse scope reading becomes more readily available, if the DP involves a clear contrast in terms of focused and nonfocused constituents (cf. ia). Under these conditions also extraction, nota bene out of a passive subject in (ib), is quite natural.

\section{(i) a. weil nur der BÜRgermeister von jeder Stadt eingeladen war since only the mayor of every city invited was \\ b. weil von jeder Stadt nur der BÜRgermeister eingeladen war} since of every city only the mayor invited was

No such information-structural condition has been reported for cases of inverse linking in English. The relevance of this extra requirement in German can then be related to the lack of an (unspecialized) operator position in the German DP as is argued below.
In the series LINGUISTIK AKTUELL/LINGUISTICS TODAY (LA) the following titles have been published thus far, or are scheduled for publication:

37. LUTZ, Uli, Gereon MÜLLER and Arnim von STECHOW (eds): Wh-Scope Marking. 2000.

38. MEINUNGER, André: Syntactic Aspects of Topic and Comment. 2000.

39. GELDEREN, Elly van: A History of English Reflexive Pronouns. Person, "Self", and Interpretability. 2000

40. HOEKSEMA, Jack, Hotze RULLMANN, Victor SANCHEZ-VALENCIA and Ton van der WOUDEN (eds): Perspectives on Negation and Polarity Items. 2001

41. ZELLER, Jochen : Particle Verbs and Local Domains. 2001.

42. ALEXIADOU, Artemis : Functional Structure in Nominals. Nominalization and ergativity. 2001.

43. FEATHERSTON, Sam: Empty Categories in Sentence Processing. 2001.

44. TAYLAN, Eser E. (ed.): The Verb in Turkish. 2002.

45. ABRAHAM, Werner and C. Jan-Wouter ZWART (eds): Issues in Formal German(ic) Typology. 2002.

46. PANAGIOTIDIS, Phoevos: Pronouns, Clitics and Empty Nouns. 'Pronominality' and licensing in syntax. 2002.

47. BARBIERS, Sjef, Frits BEUKEMA and Wim van der WURFF (eds): Modality and its Interaction with the Verbal System. 2002.

48. ALEXIADOU, Artemis, Elena ANAGNOSTOPOULOU, Sjef BARBIERS and HansMartin GAERTNER (eds): Dimensions of Movement. From features to remnants. 2002

49. ALEXIADOU, Artemis (ed.): Theoretical Approaches to Universals. 2002.

50. STEINBACH, Markus: Middle Voice. A comparative study in the syntax-semantics interface of German. 2002.

51. GERLACH, Birgit: Clitics between Syntax and Lexicon. 2002.

52. SIMON, Horst J. and Heike WIESE (eds): Pronouns - Grammar and Representation. 2002.

53. ZWART, C. Jan-Wouter and Werner ABRAHAM (eds): Studies in Comparative Germanic Syntax. Proceedings from the 15th Workshop on Comparative Germanic Syntax (Groningen, May 26-27, 2000)(Workshop). 2002.

54. BAPTISTA, Marlyse: The Syntax of Cape Verdean Creole. The Sotavento varieties. 2002.

55. COENE, M. and Yves D'HULST (eds): From NP to DP. Volume 1: The syntax and semantics of noun phrases. n.y.p.

56. COENE, M. and Yves D'HULST (eds.): From NP to DP. Volume 2: The expression of possession in noun phrases. n.y.p.

57. DI SCIULLO, Anna-Maria (ed.): Asymmetry in Grammar. Volume 1: Syntax and semantics. n.y.p.

58. DI SCIULLO, Anna-Maria (ed.): Asymmetry in Grammar. Volume 2: Morphology, phonology, acquisition. n.y.p.

59. DEHÉ, Nicole: Particle Verbs in English. Syntax, information structure and intonation. 2002.

60. TRIPS, Carola: From OV to VO in Early Middle English. 2002.

61. SCHWABE, Kerstin and Susanne WINKLER (eds.): The Interfaces. Deriving and interpreting omitted structures. n.y.p.

62. CARNIE, Andrew, Heidi HARLEY and Mary WILLIE (eds.): Formal Approaches to Function in Grammar. In honor of Eloise Jelinek. n.y.p. 